\title{
RT Reristade

\section{PROJETO POLÍTICO PEDAGÓGICO: A FILOSOFIA DE UMA ESCOLA DA REDE PÚBLICA}

\author{
Maria de Fátima Pereira da Silva ${ }^{1}$
}

\begin{abstract}
RESUMO
O Projeto Político Pedagógico é um importante instrumento de organização na dimensão política, social e pedagógica escolar. Essa ferramenta é um cumprimento das exigências da Lei de Diretrizes e Bases da educação. Este estudo tem como objetivo analisar a filosofia de uma escola de rede pública explícita a partir do seu Projeto Político Pedagógico (PPP). A pesquisa é qualitativa, de caráter descritivo e de cunho bibliográfico. Fundamentou-se nas contribuições teóricas dos estudiosos da área filosófica: Chaves (1979), Illich (1985) e Aranha (1990), dentre outros. A escola ao enfatizar que seu plano de ação é desenvolvido numa perspectiva democrática vai de encontro à sociedade liberal na qual está inserida. A valorização de ensino por meio da utilização do contexto social é parte fundamental para o estabelecimento de um ensino e aprendizagem de qualidade. O PPP é sugestivo de reestruturação.
\end{abstract}

Palavras-chave: Projeto Político Pedagógico; Filosofia; Escola Pública.

\begin{abstract}
The Political Pedagogical Project is an important instrument of organization in the political, social and educational pedagogic dimension. This tool is a fulfillment of the requirements of the Law of Guidelines and Bases of education. This study aims to analyze the philosophy of an explicit public network school based on its Pedagogical Political Project (PPP). The research is qualitative, of a descriptive and bibliographic character. It was based on the theoretical contributions of philosophical scholars: Chaves (1979), Illich (1985) and Aranha (1990), among others. The school, emphasizing that its plan of action is developed in a democratic perspective, goes against the liberal society in which it is inserted. The valuation of teaching through the use of the social context is fundamental to the establishment of quality teaching and learning. The PPP is suggestive of restructuring.
\end{abstract}

Keywords: Pedagogical Political Project; Philosophy; Public school.

\section{INTRODUÇÃO}

A construção do Projeto Político Pedagógico (PPP) é fundamental para nortear o gerenciamento, as metas, os objetivos e o caminho para a promoção de o ensino de qualidade.

O PPP escolar engloba as dimensões: política, social e pedagógica de uma instituição escolar. Sua elaboração cumpre as exigências preconizadas pela Lei de Diretrizes e Bases da educação. Essa ferramenta cujas normas são alicerçadas na gestão

\footnotetext{
${ }^{1}$ Universidade Federal de Campina Grande - UFCG
} 
democrática do ensino público na educação básica, com as peculiaridades e conforme os

seguintes princípios: participação dos profissionais da educação do PPP de cada instituição escolar;e, participação das comunidades escolar e local em conselhos escolares (LDB, 2017, p. 15).

A motivação para o estudo deste tema, deve-se ao fato do PPP ser um importante instrumento de construção coletiva no qual é explicitado a proposta escolar que norteia a execução de atividades para alcançar os objetivos preestabelecidos, fazendo com que se promova o exercício da cidadania e a edificação da identidade escolar, primando pela gestão democrática, cujas principais referências é LDB e a Base Nacional Comum Curricular (BNCC) (BRASIL, 2017).

Outra motivação é que segundo Paulo Freire, a educação tem o papel de mudar as pessoas e essas ao serem remodeladas, transformam o mundo. Porém, para que haja educação é necessário que a pessoa, além de dominar os conteúdos, que são normas sociais e valores culturais, compreenda-os, bem como entenda a sua razão de ser e venha a aceitálos somente após investigação cautelosa que abranja também possíveis alternativas (CHAVES, 1979, p. 13).

A atuação como docente se insere, nesse cenário educacional que atualmente vive uma crise em relação ao que se deve aprender e/ou ensinar em um mundo onde imperram a incerteza rodeadas pela fluidez da comunicação, o educador tem um novo papel - gestor e mediador de aprendizagem (IMBERNÓN, 2000, p.85). Nesse sentido, o PPP pode ser fundamental para a superação dessa crise.

Em análise do currículo escolar promovido pela obra "Sociedade sem escolas" da autoria de Ivan Illich, foi evidenciada que a educação pública beneficia-se da desescolarização da sociedade; assim também a vida familiar, a política, a segurança, a fé e as comunicações usufruem-se de processo análogo (ILLICH, 1985, p 16-17).

Diante do exposto, emergiu-se o seguinte questionamento: Qual é a filosofia de uma escola de rede pública explícita a partir do seu Projeto Político Pedagógico (PPP) localizada num município do Alto Sertão Paraibano?

Para responder a esse questionamento traçou-se o seguinte objetivo: analisar a filosofia de uma escola de rede pública explícita a partir do seu Projeto Político Pedagógico (PPP) de um município do Alto Sertão Paraibano.

O artigo está organizado por uma introdução aqui explicitada, a metodologia que aborda o procedimento para a construção do estudo, os resultados e discussões que elencam uma reflexão filosófica acerca das estruturas dos PPP da escola da rede pública municipal 
do Alto Sertão Paraibano, culminando com as considerações finais na qual se aborda os

objetivos que foram alcançado com o desenvolvimento dessa pesquisa.

\section{METODOLOGIA}

O estudo é do tipo exploratório que foi realizado a partir da análise filosófica do PPP de uma escola de rede pública municipal localizada num município do Alto Sertão Paraibano.

A pesquisa de caráter exploratório é preconizada para explorar um determino fenômeno, ou seja, quando se tem pouco ou nenhum conhecimento sobre a problemática. Possibilita o desenvolvimento de hipóteses para a produção de conceitos (MARCONI, LAKATOS, 2010, p. 187).

Quanto aos meios, trata-se de pesquisa documental, realizada a partir do PPP que foi fornecido pela gestão da escolas em estudo. A investigação documental faz análise de documentos organizacionais, governamentais ou mesmo de indivíduos que ainda não tenham sido averiguados (ALMEIDA, 2014, p. 28).

Optou-se por uma abordagem qualitativa. Esse tipo de abordagem tem como fonte direta de dados o ambiente natural e o instrumento fundamental é o pesquisador (GODOY, 1995, p. 62).

A coleta de dados foi realizada a partir da leitura do PPP da escola supracitada, durante o mês de julho e agosto de 2018. Teve como questão norteadora: Qual é a filosofia de uma escola de rede pública explícita a partir do seu Projeto Político Pedagógico (PPP) localizada num município do Alto Sertão Paraibano? Essa indagação foi imprescindível para a condução do desenvolvimento do estudo.

O PPP da escola foi dividido em etapas para a sua construção: A $1^{a}$ etapa refere-se às reflexões e questionamentos de seus profissionais sobre a escola hoje e o que poderá vir a ser, explicitando seus propósitos definindo em seu marco referencial a identidade da escola, aspectos conceituais, doutrinal e pedagógico. A $2^{\mathrm{a}}$ etapa diz respeito ao diagnóstico tratandose de levantar informações sobre o trabalho que a escola vem realizando e os desafios a serem enfrentados. A $3^{\text {a }}$ etapa elaboração do plano de ação com objetivos e estratégias a serem executadas para superação dos desafios. A $4^{\text {a }}$ etapa se constituirá da organização curricular e sistema de avaliação.

Foram apreciados os dados referente a $1^{\mathrm{a}}$ etapa do PPP que refere-se às reflexões e questionamentos de profissionais a escola sobre a escola na sua contemporaneidade, seu marco referencial, a identidade da escola, aspectos conceituais, doutrinal e pedagógico. 
Os julgamento dos dados foram examinados a partir de uma análise filosófica baseada nas concepções dos autores Chaves (1979), Illich (1985) e Aranha (1990), dentre outros.

A importância das reflexões filosóficas, se justifica pela própria exigência da função ser filósofo, já que "cabe aos filósofo acompanhar reflexiva e criticamente a ação pedagógica, de modo a promover a passagem de uma educação assistemática (guiada pelo senso comum) para uma educação sistemática (consolidada pela consciência filosófica)" (ARANHA, 1990, p. 105).

\section{RESULTADOS E DISCUSSÕES}

O PPP da Escola de Rede Pública em estudo discorre em sua apresentação dos princípios de equidade, eficácia e democracia, nos quais enfatiza ser pautado. Enaltece-se da premissa básica: a estrutura, organização e sistematização da política pedagógicoadministrativa da escola. Também se fundamenta na busca efetiva da melhoria, engrandecimento e desenvolvimento sólido do processo de ensino e aprendizagem, como sendo o objetivo primordial da instituição e função social da escola.

No que diz respeito à democracia, Chaves (1979) ao tentar clarificar e elucidar o conceito de educação, percebe que há um envolvimento entre educação e democracia, educação e conhecimento, educação e as chamadas potencialidades do indivíduo, etc. Envolve, também, o esclarecimento das relações que possam existir entre o processo educacional e outros processos: doutrinação, socialização, aculturação, treinamento, condicionamento, etc. Uma análise que tenha por objetivo o esclarecimento do sentido dessas noções, aplicação, implicações, e da sua relação entre si e com outros conceitos educacionais é tarefa da filosofia da educação e é condição imprescindível para a elucidação do conceito de educação. “Entendemos por 'educação' o processo através do qual indivíduos adquirem domínio e compreensão de certos conteúdos considerados valiosos" (CHAVES, 1979, p. 13). Pode ser entendida como uma ação que tem por objetivo desenvolver na criança estados físicos, intelectuais e morais (DURKHEM, 1965, p. 40). Educar é um método para o desenvolvimento de potencialidades humanas, fazer desabrochar a perfeição e a potência no homem e o que ele pode vir a ser (ARANHA, 1990, p. 148).

A insatisfação com a conjuntura do sistema educacional vigente, o fato das escolas terem se tornado burocráticas e hierarquizadoras, o desvio do ideal de levar cada indivíduo a modificar suas próprias experiências e referências em um a um processo de aprendizagem, 
ocorre a proposta de criação de um sistema alternativo, justificada por inúmeras iniciativas educacionais inconsequentes que foram e estão sendo agregadas à educação formal (PACHIONI, 2012, p.01).

A escola enfatiza no seu PPP que tem como papel diante da sociedade, propiciar ações para a efetivação dos direitos sociais, possibilitar e oferecer oportunidades para que os educandos se tornem cidadãos críticos, reflexivos e protagonistas da sua cidadania e da sua própria aprendizagem, preparando-os para a luta e o enfrentamento das desigualdades sociais presentes na nossa sociedade. Visa também o enfrentamento de desafios do cotidiano escolar, de maneira reflexiva, consciente, sistematizada e participativa, possibilitando (re)significar à ação de todos os agentes dessa instituição educativa.

Na concepção vygotskyana, o processo de aprendizagem humano se dá por meio da interação dialética com o ambiente social, através da qual o homem modifica o meio e se modifica. O destaque é do papel de mediador do professor como agente instigador do desenvolvimento psíquico (COUTINHO; OLIVEIRA, 2011 apud UNCKES, 2013, p. 04).

$\mathrm{O}$ ensino exige que professor disponha de metodologia que se adequem com os objetivos a serem atingidos em relação a aprendizagem pelos alunos. A condução do processo de ensino é tarefa do docente. Trabalhar conceitos educacionais não é uma tarefa fácil para um professor por esses conceitos divergem muitas vezes na perspectiva de vários autores. A explicação desses conceitos para os seus alunos exige, portanto, um juízo próprio de compressão que transcenda todas as discordâncias para que dessa forma os alunos também possam concordar ou discordar dos argumentos do professor e criem os seus próprios julgamentos desses conceitos.

A missão da escola é contribuir na formação educativa de cidadãos autônomos, independentes para atuar em sociedade de modo interativo, reflexivo, crítico e eficiente com a visão de ser reconhecida como instituição educativa com capacidade de desenvolver a qualidade e a excelência nos processos de ensino e aprendizagem.

A concepção de Illich (1985) se contrapõe a essa missão da escola, ou seja, essa missão não é possível alcançar por uma instituição de ensino, já que essa limita a imaginação dos alunos, ambiente homogeneizador do pensamento, onde a aprendizagem é o resultado do ensino e a sabedoria institucionalizada tendo como conseqüência a realidade social escolarizada situa-se na modernização da pobreza. A escola para o autor, não é um espaço de reflexão, participação e sistematização do conhecimento, mas de monopolização. 
Os valores são centrados na gestão democrática, no respeito à diversidade e a dignidade humana, comprometimento social, qualidade de ensino, competência técnica e intelectual e respeito às diferenças.

Amenizando as críticas em relação à instituição escola no sentido de diminuir os relatos verbalizados de que é "a escola mera reprodutora de desigualdades sociais" e evitando gerar um "pessimismo imobilista", assim como outros debates contraditórios refletem que a classe dominante impõe seus valores, porém a classe dominada não se subordinam assim tão inerte (ARANHA, 1990, p .192)

Em termos de marco referencial a escola apresenta o seu marco situacional inserida num meio de externa pobreza e carências sociais. Está situada num bairro periférico, com considerável incidência de criminalidade e de marginalização, tráfico de drogas, prostituição, violência familiar, desemprego, carências múltiplas, principalmente afetiva, por parte do educando.

\begin{abstract}
Os pobres sempre foram socialmente impotentes. A crescente confiança nos cuidados institucionais adiciona nova dimensão à sua impotência: impotência psicológica, incapacidade de defender-se. [...] Passam a depender também de chefes políticos e são desqualificados por causa da falta de escolarização. A pobreza moderna combina a falta de poder sobre as circunstâncias com a perda de força pessoal. Esta modernização da pobreza é um fenômeno universal e está na raiz do subdesenvolvimento contemporâneo. Manifesta-se, obviamente, de formas diferentes nos países ricos e pobres (ILLICH 1985, p. 18).
\end{abstract}

Muitos são os desafios de uma escola situadas em locais de extrema pobreza onde os problemas sociais nem sempre são considerados para a elaboração de políticas que viabilizem uma educação de qualidade. Para Illich, a falta de escolarização converge para políticos despreparados, ou seja, uma pobreza moderna que não tem poder para lutar pela mudança da realidade social vivenciada.

Em se tratando do marco doutrinal o PPP sublinha que diante do contexto de uma sociedade globalizada e sem fronteiras, a educação que almejamos há muito tempo tem por finalidade o respeito, a igualdade e a liberdade. Com a formação de indivíduos solidários, participativos e conscientes de si mesmos, de seu lugar no mundo e de suas responsabilidades perante a natureza e a sociedade organizada. E, que encontre em sua forma de participar dessa sociedade, o prazer dela pertencer. E acrescenta que a educação tem um papel importante na construção da sociedade e na formação do indivíduo diante da complexidade que envolve a relação homem/sociedade. Assim, deve-se implantar na escola uma proposta através da qual o 
aluno, de posse de seus conhecimentos anteriores e com dados novos obtidos através da

interação com o professor, com seus colegas, com seu contexto social e pela intervenção destes, possa construir e reconstruir o seu conhecimento e assim implantar mudanças na sociedade.

O marco doutrinal explicitado aqui pela escola se distancia da realidade a ser alcançada na concepção de um defensor de uma sociedade desescolarizada. Predomina no âmbito escolar "a sabedoria institucionalizada nos diz que as crianças precisam de escola", porque nessa sabedoria institucionalizada revela que a só aprende na escola. Mas esta "sabedoria institucionalizada é produto de escolas". "Somente pela segregação dos seres humanos na categoria infantil conseguimos submetê-los à autoridade de um professor escolar" (ILLICH 1985, p. 43). Com isso, os conhecimentos prévios dos alunos não são considerados no processo de ensino.

De forma detalhada, enaltece que a escola em estudo, em seu PPP, é um meio de construção de conhecimentos e formação da criança, do jovem e do adulto. Mas, para que a escola cumpra efetivamente o seu papel é necessário o conhecimento das necessidades dos alunos e da comunidade na qual está inserida. Daí a importância de uma escola com objetivos inovadores capazes de modificar a estrutura de pensamento, de raciocínio, de interesses dos indivíduos envolvidos no processo.

Essa abertura para a inovação que proporcione conteúdos de interesse dos alunos só foi possível quando passou a se refletir sobre os currículos escolares. Neste sentido a Filosofia da Educação teve um papel preponderante na acepção das discussões no que diz respeito a Pedagogia, nos anos 1970, quando culminou no Brasil, para a reformas curriculares e institucionais influenciadas pelos ideários da Escola Nova . Foi a partir da metade do século XX que operacionalizou uma transformação no conceito de Pedagogiaa que harmonizou sua identidade, limites e consequentemente "o papel atribuído à Filosofia como saber sobre a educação" (AGUIAR, WELLER, 2016, p. 02). "Da pedagogia passou-se à ciência da educação; de um saber unitário e 'fechado' passou-se a um saber plural e aberto: do primado da filosofia passouse aos das ciências" (CAMBI, 1999, p. 595).

Com esse mesmo propósito, a escola tem o desígnio de "ensinar a repensar o pensamento", a 'des-saber' o sabido e a "duvidar de sua própria dúvida; esta é a única maneira de começar a acreditar em alguma coisa" (MORIN, 2003, p.19). Ensinar a pensar é mostrar o caminho para a construção de uma consciência crítica. De acordo com Morin, é preciso instruir aos discentes a repensar o pensamento, instigar a curiosidade, a participação 
efetiva do destes no processo ensino/aprendizagem e valorizar os conhecimentos prévios e o

contexto social doas aprendizes.

A iniciativa de construir conhecimento para produzir aprendizagens significativas e sistematização do conteúdo deve ser impulsionada no ambiente escolar, já o preparo de todo ser humano se dá por meio da educação para que possa "elaborar pensamentos autônomos e críticos e formular os seus próprios prejuízos de valor, de modo, a poder decidir, por si mesmo, como agir nas diferentes circunstâncias da vida (DELORS, 2001, p. 117). Corroborando com esse autor, o objetivo da educação não é transmitir conhecimentos sempre mais numerosos ao aluno, mas o "de criar nele um estado interior e profundo, uma espécie de polaridade de espírito que oriente em um sentido definido, não apenas durante a infância, mas por toda a vida"(MORIN, 2003, p.47).

Quando a escola se preocupa em desenvolver competências, os conteúdos deixam de ser um ponto essencial do processo; o professor passa de transmissor do conhecimento a facilitador da aprendizagem; a avaliação, de classificatória e excludente, se transforma em instrumento para guiar intervenções pedagógicas; o aluno, antes passivo, vira participante ativo na construção do próprio conhecimento.

O aluno sendo o protagonista na construção do conhecimento, exige que o professor exerça uma prática respaldada na interdisciplinaridade para se chegar a edificar a prática transdisciplinar e dar conta de uma prática hoslístico. Para isso, exige a aprender a ser, a fazer, a viver juntos e conhecer, pilares essenciais que traz implicações sobre a prática pedagógica (DELORS, 2001). Esses pilares devem nortear debates para o aprofundamento, e de fato, construir práticas pedagógicas em sua excelência.

Cabe a Filosofia desenvolver uma reflexão numa perspectiva globalizante e holística examinando os problemas, nesse caso educacionais, e seus diversos aspectos na busca da visão em sua totalidade, tendo, dessa forma, a função interdisciplinar estabelecendo um elo entre as diversas formas de saber e do operar humanizado (ARANHA, 1990, p. 107).

A escola é responsável pela promoção do desenvolvimento do cidadão, no sentido pleno da palavra. Então, cabe a ela definir-se pelo tipo de cidadão que deseja formar, de acordo com a sua visão de sociedade. Essa instituição também a incumbência de definir as mudanças que julga necessário fazer nessa sociedade, através das mãos do cidadão que irá formar.

Assim, através da implantação de atitudes e metodologias que valorizam o educando, como um participante ativo e não mero expectador do processo de ensino e aprendizagem, a escola assumirá seu verdadeiro papel na sociedade que é o de contribuir para formação cidadã 
dos educandos através do desenvolvimento do prazer em aprender, da valorização cultural, do

respeito e tolerância às diversidades, respeito a natureza e a sociedade como um todo. A esse respeito, é empacado um debate que vai a contraponto, a escola é uma instituição de controle, com protocolares de provas e fantasia do diploma não valorizando aquele que busca aprender por si mesmo (ARANHA, 1990, p .197).

O marco pedagógico ou operativo da instituição em estudo ressalta que escola deve ser envolvida na construção do conhecimento com atualizações, que proporcione a todos os estudantes o acesso as mais diferentes formas de cultura; que seja protagonista na inovação dos conteúdos, métodos e gestão, com o objetivo de desenvolver plenamente as potencialidades e descobertas dos discentes, para que eles se tornem cidadãos autônomos, solidários e competentes. Nesse sentido, a escola é um local de trabalho que fornece serviço profissional à coletividade, mas é influenciada pela sociedade na qual está inserida.

$\mathrm{O}$ ambiente escolar transmite ideias e valores que justificam a práticas sociais excludentes da herança cultural (ARANHA, 1990, p .29). Corroborando com essa ideia,, o processo educacional, bem como outros processos: “doutrinação, socialização, aculturação, treinamento, condicionamento, etc." excluem o contexto cultural. Tais processos estão envolvidos numa relação de proximidade para o esclarecimento do conceito de educação através da Filosofia da Educação (CHAVES, 1979, p. 04).

O PPP tem a expectativa de tornar o estudante um sujeito ativo no processo de ensino e aprendizagem e não um mero receptor do conhecimento. O professor, por sua vez, é um mediador desse conhecimento, haja vista que, busca oportunizar atividades e situações para que o estudante possa desenvolver suas competências e habilidades. Acredita-se que o educarse é relação de complementaridade entre estudante e escola.

Mediante essa percepção do papel da educação através da escola e do educador adotase a Tendência Pedagógica Crítico-Social dos Conteúdos. Nessa tendência, há uma mediação do saber por parte do professor, e o estudante é estimulado a confrontar as suas experiências com o saber sistematizado, tendo em vista promover o domínio dos conhecimentos, habilidades e capacidades mentais para organizar, interpretar e reelaborar as suas expectativas de vida em função dos interesses da classe. O ensino consiste na mediação de objetivosconteúdos-métodos que assegure o encontro formativo entre os estudantes e as matérias escolares, fator decisivo da aprendizagem.

A Pedagogia Crítico-Socail dos Conteúdos também conhecida como Pedagogia Dialética e atualmente denominada de Pedagogia Histórico-Crítica tem como principal representante Dermeval Saviani, dentre outros como José Carlos Libâneo, Carlos Roberto 
Jamil Cury, Guiomar Gamo de Mello, etc. Constitui um projeto pedagógico cuja tarefa

consiste na tentativa de reversão da realidade educacional buscando compreender a realidade histórica e social com a finalidade de mediar a transformação da educação para provocar mudanças sociais de forma mediatizada por meio da transformação das consciências (ARANHA, 1990, p .215-216).

Agregados a essa tendência a valorização dos conteúdos no enfrentameto da realidade social e política é relevante seguir os princípios éticos, morais, espirituais, de sustentabilidade e respeito à diversidade que possam fundamentar efetivamente a prática pedagógica.

Dizer que a escola em estudo se insere no contexto para o desenvolvimento das atividades numa perspectiva democrática é um paradoxo, pois essa escola é engrazada na sociedade capitalista.

A salvaguarda da liberdade individual fica suspensa no relacionamento de um professor com seu aluno. Quando o professor reúne em sua pessoa as funções de juiz, ideólogo e médico perverte se o estilo fundamental da sociedade pelo mesmo processo que deveria preparar para a vida. Um professor que reúne esses três poderes contribui muito mais para a distorção da criança do que as leis que determinam sua minoridade legal e econômica, ou que restringem seu direito à livre reunião e residência (ILLICH 1985, p. 43).

O exercício da democracia é impossível numa sociedade liberal, já que os direitos individuais se sobrepõem aos coletivos.

A escola ao se pensar em qualidade do ensino, é necessário não se esquecer do contexto no qual a escola está inserida. O que sucede dentro da sala de aula possui uma autonomia relativa que é fortemente influenciada pelo contexto social (SILVEIRA, SANTOS e FAJARDO, 2013). Por isso, é importante o professor fazer um paralelo entre os conteúdos trabalhados associando a situações cotidianas.

\section{CONSIDERAÇÕES FINAIS}

Analisar a filosofia de uma escola de rede pública explicitada a partir do seu PPP constituiu um desafio em virtude da dificuldade de referências sobre a temática. Neste sentido, o desafio foi superado.

O estudo possibilitou identificar o paradoxo existente no PPP da escola objeto desse estudo. Ao enfatizar que seu plano de ação é desenvolvido numa perspectiva democrática vai a contraponto à sociedade liberal na qual está inserida, sendo sugestivo de reestruturação. 
Os resultados da pesquisa podem servir de fonte de informações para a reestruturação

de PPP da escola estudada, bem como de outras escolas. Além disso, pode fornecer subsídios para pesquisadores e/ou curiosos que queiram expandir pesquisas relacionadas a esse tema, resultando em novos focos de análise por meio desses dados.

A valorização de ensino por meio da utilização do contexto social é parte fundamental para o desenvolvimento de um ensino e aprendizagem de qualidade. Porém isso deve deixar de ficar apenas documentado PPP escolar e fazer parte da realidade vivenciada por discentes em sala de aula e em todo o estabelecimento de ensino, sem incoerência da atuação autônomo do desse ator social na construção do conhecimento. Com isso, é possível alcançar o êxito da melhoria da qualidade do processo de ensino-aprendizagem.

\section{REFERÊNCIAS}

AGUIAR, T. B. P.; WELLER, W. Filosofia da Educação no Brasil: a trajetória de uma disciplina e sua constituição como campo de pesquisa. Encontro de Pesquisa em Educação da Região Centro Oeste - Reunião Científica Regional da ANPEd: Projeto Nacional de Educação: desafios éticos, políticos e culturais. Anais. Brasília: Universidade de Brasília, ANPEd, 2016.

ALMEIDA, M. S. Elaboração de Projeto, TCC, Dissertação e Teses: uma abordagem simples, prática e objetiva. São Paulo: Atlas S.A, 2014.

ARANHA, M. L. A. Filosofia da Educação. São Paulo: Moderna, 1990.

BRASIL. Ministério da Educação. Secretaria da Educação Básica. Fundamentos pedagógicos e estrutura geral da BNCC. Brasília, DF, 2017. Disponível em:

<http://portal.mec.gov.br/index.php?option=com_docman\&view=download\&alias=56621bnccapresentacao-fundamentos-pedagogicos-estrutura-pdf\&category_slug=janeiro-2017pdf\&Itemid=30192>. Acesso em: ago. 2018.

CAMBI, Franco. História da pedagogia. São Paulo: Ed. Unesp, 1999.

CHAVES, E. O. C.. A Filosofia da Educação e a Análise de Conceitos Educacionais. In REZENDE, A. M. (org.), Iniciação Teórica e Prática às Ciências da Educação. Petrópolis: Vozes, 1979.

DELORS, J. Educação um tesouro a descobrir. Relatório para a Unesco da Comissão Internacional sobre a Educação para o Século XXI. Trad.

José Carlos Eufrázio. São Paulo: Cortez, 2001.

DELORS, J. (Org.). Os quatro pilares da educação. In: Educação: um tesouro a descobrir. São Paulo: Cortezo, 2001. 
DURKHEIM, E. Educação e sociologia. Trad. Lourenço Filho. São Paulo: Melhoramentos,

1965.

GODOY, A. S. Introdução a pesquisa qualitativa e suas possibilidades.

Revista de Administração de Empresas. São Paulo, v. 35, n. 2, p. 57-63, Mar./Abr. 1995B.

ILLICH, Ivan. Sociedade sem Escolas.Petrópolis: Vozes, 1985

IMBERnÓN, F. (Org.) A educação no século XXI. Porto Alegre: ARTMED, 2000.

LDB: Lei de diretrizes e bases da educação nacional. - Brasília : Senado Federal, Coordenação de Edições Técnicas, 2017.

MARCONI, M. A.; LAKATOS, E. M. Fundamentos da metodologia cientifica. São Paulo: Atlas, 2010.

MORIN, E. (2003). A cabeça bem feita: repensar a reforma, reformar o pensamento. Rio de Janeiro: Bertrand Brasil, 2003.

PACHIONI, M. S. A desescolarização da sociedade para a construção do conhecimento. Revista Ação Midiática - Estudos em Comunicação, Sociedade e Cultura Universidade Federal do Paraná Programa de Pós Graduação em Comunicação, v. 2, n. 2, 2012.

SILVEIRA, J. B.; SANTOS, R. C. G.; FAJARDO, G. P. A Educação em Transição do Século XX ao XXI: novos caminhos?! In: Sociologia da Educação: debates contemporâneos e emergentes na formação de professores. Rio Grande: Editora da FURG, 2013.

UNCKES, R. C. A prática docente em sala de aula: mediação pedagógica. V Simpósio para a formação de professores da Educação Básica: desafios frente às desigualdades educacionais. Anais. Tubarão - SC: Campus Universitário, 2013. 